\title{
Chemical Castration: International Experience and Chinese Path to Control Pedophilia Crimes
}

\author{
Jin Zhuang \\ Law School, Sun Yat-sen University, Guangzhou, China \\ Email:13503035925@126.com
}

How to cite this paper: Zhuang, J. (2018). Chemical Castration: International Experience and Chinese Path to Control Pedophilia Crimes. Advances in Applied Sociology, 8, 575-597.

https://doi.org/10.4236/aasoci.2018.88034

Received: June 25, 2018

Accepted: August 6, 2018

Published: August 9, 2018

Copyright $\odot 2018$ by author and Scientific Research Publishing Inc. This work is licensed under the Creative Commons Attribution International License (CC BY 4.0).

http://creativecommons.org/licenses/by/4.0/

\begin{abstract}
The current penalties in China are not sufficient to effectively curb pedophilia. Chemical castration is not the corporal punishment in real sense but indicates reducing the medical treatment of the criminal's lust by injecting anti-androgen drugs without causing perpetual harm to the criminal's body. It includes many aspects such as penalty execution procedure \& object, treatment position, and penalty execution replacement \& guarantee, etc. There are characteristic regulations on it in many states of America. The drastic argument on issues including the constitutionality, fairness, effectiveness and economy of the penalty is held in the American academic circle. Chemical castration has remarkable effect in urging catamite crime, which is worth of referring to for Chinese criminal law. However, it is necessary to take precaution against the limitation in design of the specific system.
\end{abstract}

\section{Keywords}

Chemical Castration, Catamite Crime, Sexual Crime

\section{Introduction}

There is a growing trend in the crime of Pedophilia in China. According to the report of the Guangdong Provincial Procuratorate of China in 2012, from 2008 to 2011, the procuratorates in Guangdong Province accepted 2267 cases involving female victims under the age of 18 years. 1708 cases involves sexual assault, which takes up $75.34 \%$ of cases received, and $49.28 \%$ cases involves victims under the age of 14 (Guangdong Provincial Procuratorate, 2012). This means nearly half of the 2267 cases involve sexual assault targeting girls. In recent years, chemical castration has been carried out in more and more countries as a punishment to curb child-molestation crimes, but whether chemical castration is suitable for deterring child molestation in China, and whether it is an inhumane 
punishment, are still not well discussed in the academic literature.

Therefore, the purpose of this paper is to explore the legitimacy of chemical castration and the feasibility of incorporating it into China's penal system. Section 1 will discuss the defects of China's current measures to correct child molesters. Section 2 will introduce the drug function of chemical castration and the effectiveness of crime prevention. Section 3 will introduce the framework of American chemical castration system. Section 4 will demonstrate the justification of chemical castration. In Section 5, I will discuss the idea of constructing chemical castration system in Chinese criminal law.

\section{Chinese Punishment of Pedophilia Crimes and Its Problems}

There is no article specifically against sexually molesting children in Chinese Criminal Law. It is regulated in rape crime (article 236) and indecency crime (article 237) with a heavier penalty if the victims are children. The defendant committing indecency crime can be sentenced to 15 years' imprisonment at most and rapists can be sentenced to death penalty as the severest punishment. In most cases, criminals committing these two crimes are sentenced to fix-term imprisonment instead of death penalty if no victim is dead or their crimes didn't cause additional severe social impact. In the meantime, well-behaved criminals can have the opportunity of commutation which means their penalty can be reduced to half of the original one at most according to Chinese commutation system. It means that most pedophile criminals can return to the society really fast so it is important to prevent them from committing crimes again.

Actually, penalty in Chinese Criminal Law is not enough to restrain pedophilia crime. The criminal sentenced to fix-term imprisonment is transported to prisons to serve his sentence and the main punishment and correction measure is forced labor. According to the article 46 of Chinese Criminal Law, criminals sentenced to fix-term imprisonment, life imprisonment are executed in prisons or other executive sites and whoever is with working capability should participate in working to be educated and reformed because Marxism is considered to be the guiding ideology of Chinese prison system. In Marx's point of view, history is just the process of the birth of human through labor (Max \& Engels, 1979: p. 131). He then connects labor and crime prevention and believes that physical labor is disinfectant to prevent all kinds of disease in the society (Max \& Engels, 1972: p. 538). According to this ideology, article 70 of Chinese Prison Law states that criminals in prison should participate in labor according to his personal condition to correct his bad behavior, to develop the habit of working and to learn production skills in order to obtain employment after released. Labor is considered to be the main method to correct criminals' habit of committing crimes. Many scholars also believe that the foundation of Chinese prison system is labor transformation of criminals (Wang, 2010: p. 43) and labor is the most important measure to remold criminals (Liu, 2001: p. 149). It is believed that 
there are four functions of labor in the penalty execution process: firstly, it is safe. Criminals are working five days a week and it takes up most of their serving time and makes the prison safer. Secondly, it punishes criminals by making them suffer from labor during the execution of penalty. Thirdly, criminals acquire working skills which is to the benefit of their returning to the society. Fourthly, it is good to the economics by covering the shortage of national expenditure in prisons (Wang, 2010: p. 43).

However, labor is not an efficient method to prevent pedophile criminals from committing crimes again. The American scholar Hottle divides sexual criminals into four types according to their behavior after committing the crime: firstly, the criminals commit crimes out of lust and this type of criminals usually refuse to admit to their wrong behaviors. Secondly, this type of criminals admits to their sexual crime but they attribute their responsibility to the reasons except the sexual impulse, like drug addiction, drunkenness or high tension. The third type of criminals are the violent criminals whose motivation is not to purely satisfy their sexual lust but out of outrage, lust for power or inclination for violence. The fourth type of criminals is those commit crimes out of abnormal sexual preferences and sexual psychological disorder such as pedophilia, fetishism, zoophilia etc. (Hottle, 1992-1993: p. 307). Obviously, all of these four kinds of criminals act out of sex lust and except the first kind, their motives also include other factors. According to Chinese scholars' research into the biology condition of sex offenders, the endocrine level of male sex offenders is abnormal. Their free testosterone level is higher than the control group and they might suffer from pituitary-testicular axis dysfunction (Wu, 1995: p. 26). Marx's opinion that labor promotes the progress of human society is based on the observation of the development of human society on the macro level. Microscopically, there is no obvious relationship between labor and sex crimes. Labor can neither change the endocrine levels of the criminals nor teach them to control sexual desire. It is impossible for labor to cure them, especially the fourth kind of criminals because they violate children out of mental disorder and the cause of it may be the excessively high sex hormone level.

Meanwhile, the possibility of the second offense of the pedophile criminal is irrelevant to the commutation. According to the article 78 of the Chinese Criminal Law, criminals can be commuted if they obey the regulation of the prison, accept educational reform and show sincere repentance. The core elements of the standard of the commutation are abidance by regulations of the prison and active participation in labor. It is impossible for criminals to contact with children and the opposite sex so the reason of the abidance of the pedophile criminal may be the lack of opportunity to contact with targets. Pedophile criminals who get high scores in the commutation investigation may still have high sexual desire. Getting high scores doesn't mean that they have learned to reconcile the conflict between their sexual desire and the law. They may still become horrible perpetrators when they are released and find proper victims. 
Chinese sexual crimes number and the recidivism rate have been high because the penalty is not pertinent. According to the National Bureau of Statistics of China, there were 27,767 rapes that were brought to the case filing process which means there was a rape approximately every 19 minutes (Tian, 2017: p. 64). And according the report published by Chinese Children's Culture and Art Foundation, there were 433 cases of sexual assault against children (under 14 years old) reported by Chinese media in 2016, an increase of 27.35\% compared with 2015 (Chinese Children's Culture and Art Foundation, 2016). What's worse, the recidivism rate of sexual crimes is high. Chinese scholars collect 451 samples of criminals who committed sexual crime again after being punished with criminal penalty due to molesting from January, 2006 to January, 2016 on the pkulaw.cn and China Judgements Online. They find out that the recidivism rate of criminals who first committed indecency to females over 14 is 16.7 while that of the criminals whose victims were under 14 is $40.8 \%$. The data are as follows.

\begin{tabular}{|c|c|c|c|c|c|}
\hline $\begin{array}{l}\text { The } \\
\text { former } \\
\text { crime }\end{array}$ & $\begin{array}{l}\text { The number } \\
\text { of the former } \\
\text { crime }\end{array}$ & Rape & $\begin{array}{c}\text { Indecency } \\
\text { (victims over 14) }\end{array}$ & $\begin{array}{c}\text { Indecency } \\
\text { (victims under } \\
\text { 14) }\end{array}$ & $\begin{array}{l}\text { The } \\
\text { recidivism } \\
\text { rate }\end{array}$ \\
\hline $\begin{array}{l}\text { Indecency } \\
\text { (victims } \\
\text { over 14) }\end{array}$ & 96 & 2 & 14 & 0 & $16.7 \%$ \\
\hline $\begin{array}{l}\text { Indecency } \\
\text { (victims } \\
\text { under 14) }\end{array}$ & 355 & 8 & 110 & 27 & $40.8 \%$ \\
\hline
\end{tabular}

The accurate recidivism rate may be even higher, for there may be crimes that weren't included in the official number. This shows that Chinese penalty is not effective enough to prevent sexual crimes especially in the case of released pedophile criminals' re-offending so we need to introspect on the correction measures of pedophile criminals. Chinese scholars studying pedophile crimes have realized that we can take drug therapy along with cognitive therapy, conditioned reflect therapy (Jiang, 2008: p. 569; Liu, 2017: p. 82). However, cognitive therapy and conditioned reflect therapy are mental therapy which are not compulsory and difficult to be included in the criminal penalty. Since the biological basis of the sexual criminals is abnormal endocrine, why don't we consider control their androgen level with compulsory medical methods in order to restrain their desire to commit crimes thereby preventing sexual crimes? Thus, it is necessary for us to refer to other countries' chemical castration systems.

\section{Mechanism and Effect of Chemical Castration}

\subsection{Background of Chemical Castration}

Chemical castration is the penalty which injects the sex offenders with anti-androgen to prevent them from a second offense. The original intention of the anti-androgen chemical castration (hereinafter referred to as "chemical castration") is to urge pedophilia crime. Statistically, 25\% of American females were 
sexually molested in the childhood (Blume, 1990: p. xiv); another research shows that $2.5 \%-26 \%$ of boys were sexually molested before the age of 18 (Hunter, 1990: p. 3). When staying with children, the child molester could generate the sexual lust out of control. Anyway, such lust couldn't be satisfied in "red light district" where most services are sexual services provided by adults. In consequence, the recidivism rate of pedophilia crime has always been high. According to the official statistics of California, there are about 66,000 sex offenders registered across the state, of which about 33,000 are sexual child molesters. $50 \%$ of these criminals recommitted crime again in the first year after released conditionally. However, this number would rise to $80 \%$ the next year (Office of Governor Pete Wilson, 1996: p. 1). The child molesters will still commit crime again under the drive of sexual lust even in the face of actual and instant imprisonment and even the lifetime imprisonment or death penalty (Flack, 2005: p. 173). To urge pedophilia crime, surgical castration has been executed for the severe sexual offenders in the European countries since 1906 and some states in America since 1940s (Office of Governor Pete Wilson, 1996: p. 309). However, the punishment of testicular excision is considered to be cruel and inhuman. In order to protect children and stick to the baseline of humanism, the chemical castration is put on the historical stage.

According to the discovery of John Money, the professor from Johns Hopkins University, the child molester's desire to commit crime was reduced by controlling the hormone concentration in man's blood using contraceptive for females "medroxyprogesterone acetate" in 1966 (Rundle, 1996: B1). However, the drug has not been permitted by American FDA for a long time, so chemical castration has not been legislated in America until 1992 when medroxyprogesterone acetate was permitted by the American government as a legal medicine with the trademark of "Depo-Provera". Four years later, California passed the act of chemical castration and became the first state determining the system in America. Afterwards, many states, including Florida, Georgia, Iowa, Montana, Oregon, Wisconsin and Louisiana, established the system of chemical castration one by one ${ }^{1}$. Though chemical castration was proposed to cope with pedophilia crime, its pharmacologic mechanism could also have the same prevention effect on general sexual crime. Therefore, its applicable objects were expanded to the adult sexual offenders in the legislation in America later.

\subsection{Mechanism and Effectiveness of Chemical Castration}

Medroxyprogesterone acetate is the officially recommended drug for chemical castration, abbreviated as MPA and usually called as MPA treatment according to the legislation of America. MPA indicates a kind of drug acting on the cells related to the sex in the brain. Its mechanism of action: accelerate the metabol-

${ }^{1}$ Chemical castration was abolished in George and Oregon in 2006 and 2011 respectively, the reason for which the Ga. Code Ann. $\$ 16-6-4$ (repealed in 2006); Or. Rev. Stat. Reason for abolishment in George is and Oregon is that there are no medical practitioners found to be willing to execute medical punishment. Ann. $\$ 144.625$ (1) (2006) (repealed by Law 2011, c. $419 \$ 1$, eff. June 17, 2011). 
ism of the androgen of the drug taker namely the testosterone by injecting the medicine, and inhibit the releasing of luteinizing hormone (IH) in pituitary gland to reduce the level of in vivo testosterone of the drug taker (Brody \& Green, 1994: p. 350). The reason that people call it "chemical castration" is that it reduces the androgen in criminals through chemistry of the drug. Its effect is similar to the traditional surgical castration by inhibiting the sexual lust of the executed person.

However, chemical castration, not the real castration, is officially called "treatment" according to the legislation of America, which means that is just a kind of medical treatment approach rather than the traditional corporal punishment. It will neither destroy the completeness of the executed person's body nor will it destroy his sexual function forever. Drug injection only reduces but not eliminates the androgen of the executed person, and they will not become feminine and impotent hereupon. Some research even points out that they can still have normal sexual life under the stimulus of his mate or researcher. Such treatment is revertible. The criminal's androgen can be recovered to the level before it is put to torture within two weeks after drug discontinuance (Fitzgerald, 1990: p. 7). Of course, MPA also has some adverse effects, like weight gain, night sweat, nightmare, myasthenia and fatigue, etc. (Peters, 1993: p. 311). It may also be relevant to the following symptoms such as gallbladder dysfunction, large intestine diverticulitis, diabetes, phlebitis, dyspnea, hyperglycemia, leg cramps, drop of chaeta and increased temperature, etc. (Fitzgerald, 1990: p. 7). However, the researcher points out that the abovementioned adverse effects seldom occur and may be reversible even if occurring, but the symptom usually disappears fast once in case of drug discontinuance (Fitzgerald, 1990: p. 7).

Chemical castration is very popular in Europe and America, for which it inhibits the sexual crime obviously. From 1989 to 1996, 26 criminals in Denmark's prison chose hormone injection, of which 16 were sentenced in consequence. However, only 1 of these 16 recommitted the crime afterwards (St. Louis Post-Dispatch, 1996: p. 4D). After the androgen inhibiting drug was injected to the sexual offenders in many European countries such as Sweden and Germany, the recidivism rate dropped to $2.2 \%$ from originally nearly $100 \%$ (Gimino III, 1998: p. 100). Johns Hopkins University once implemented a follow-up study on 626 sexual offenders who received MPA. Their recidivism rate was lower than $10 \%$ in 5 years. By contrast, the recidivism rate of sexual crime in America at the same period was approximately $65 \%$. Among 20 pedophilia criminals receiving testosterone inhibiting drug in the research presided over by Doctor Berlin, only 1 recommitted the crime within 1 year after taking drug. The recidivism rate was $5 \%$. In his another research, he implemented follow-up study on 48 criminals receiving the treatment, in which only 7 recommitted the crime within 3 years. The recidivism rate was 14.6\% (Taylor \& Kirk, 1987: p. 1). In the research of Doctor Kravitz, abnormal fantasy and lust of 39 criminals receiving the treatment completely disappeared averagely after two weeks and only 1 reported re- 
committing the crime within 6 months after treatment, but no one was under arrest again (Kravitz et al., 1995: p. 21).

\section{System Framework of Chemical Castration in the US}

With different characteristic system design of chemical castration in numerous states in America $^{2}$, different legislation models of all states will be given into consideration in the following discussion as far as possible.

\subsection{Execution Procedure of Criminal Punishment}

1) Regular injection of anti-androgen

MPA is a common drug for penalty execution in all states in America. Though MPA could be taken orally, the effect of MPA could be maximized through injection. Therefore, the duration that the criminal receives intramuscular drug injection is regulated in all states. The efficacy of MPA is time-based, so at least $500 \mathrm{mg}$ of the drug should be injected to the criminal through arm or hip muscular injection every week (Gimino III, 1998: p. 74). There are two models of the regulation of injection period: firstly, the indeterminate sentence model, which means that the drug should be injected to the criminal one week before conditional release until the Department of Corrections submitted the proof to the Board of Prison Terms saying that the criminal no longer would need the drug treatment in the criminal law of California. It means that the term of penalty is not determined but depends on the observation and judgment of the Department of Corrections and Board of Prison Terms. Secondly, the judgment determination model, which means that the court should specify the term of penalty for the criminal to receive treatment in the judgment according to the regulations of the criminal law of Florida. Of course, the court can sentence the criminal to receive lifelong drug if necessary.

2) Procedure for penalty execution identification

The so-called procedure for penalty execution identification indicates the court assigns the expert to evaluate the psychology and physiology of the defendant to decide whether the drug treatment should be implemented. According to the criminal law of California, the execution decision procedure is not regulated at all. The sexual offenders who recommit the crime should accept drug treatment. However, such legislation model is criticized. Sexual offenders include not only men but also women. The anti-androgen injection may not be effective to female defendants. Even if it is male defendant, his criminal reason is not pure the in vivo hormone. Therefore, the drug treatment is completely effective (Stadler, 1997: p. 1316). Whereas, the expert evaluation procedure is regulated according to the legislation of all states. For instance, according to the criminal regulations of the Louisiana, the specific sexual offender should accept the ex-

${ }^{2}$ Regulations for chemical castration in each state are as below: California, Penal Code, \$645; Florida, \$794.0235; Louisiana, \$15:538; Montana, \$45-5-512; Wisconsin, \$302.11; Iowa, \$903B.10. The source will not be indicated repeatedly in the following context. 
pert's "mental health evaluation" before the suspended sentence, conditional release or delayed judgment. The evaluation report includes the identification of "the treatment scheme whether the drug injection is preferential". Iowa also regulates that even if the case belongs to the situation that it "shall be" judged as drug treatment and if the court or parole board thinks that it may be ineffective to the criminal, its application still can be eliminated. In this way, the court can execute its discretionary power to choose the criminal that is suitable to the drug treatment.

3) Informed consent procedure

The criminal still have a choice after the court decides to implement drug treatment for him. Before penalty execution, the court should execute the procedure for "informed consent" to notify the criminal of curative and side effects of MPA injection and have the criminal sign the informed consent form for confirmation. The regulation originates from "informed consent principle" determined in the Canterbury v. Spence case ruled by United States Federal Courts. That is, the doctor is obligatory of releasing all related information to the patient, including the risk in treatment, expected effect, the result of no treatment and other alternative solutions ${ }^{3}$. Therefore, before penalty execution, the criminal is entitled to know: 1) side effect and risk of MPA;2) inhibiting effect of his hormone level and sexual lust; 3) the possibility of recommitment; 4) alternative treatment schemes (Gimino III, 1998: p. 97). The criminal is entitled to reject the penalty after knowing about the fact but he won't obtain related preferential penalty, like conditional early release therefore. He may also suffer from surgical castration which is more severe.

\subsection{Object of Penalty}

The object of the drug treatment is sexual offenders. However, there is a large difference in limitation of the specific object according to the legislation of all states. To be specific, it includes two aspects as below:

1) Whether the age of the victim or defendant is limited.

According to the regulations of criminal law of California, the objects of MPA injection should be criminals who assault children under 13 years old. The crime committed by them is also limited to four types: sodomy, obscenity, seductive behavior, oral sex and insertion of foreign matter ${ }^{4}$, the last of which indicates, to satisfy the sexual lust, inserting all possible foreign matters into other's genital organ or anus or having others insert foreign matters into the genital organ or anus of the perpetrators themselves or a third party. Meanwhile, according to the regulations of criminal laws of Iowa, chemical castration is only applicable when the victim of the severe sexual crime is under 12 years old.

Contrarily, there is no restriction in the age of the victim in Florida. According to the regulations of the criminal law, the objects of drug treatment are 
"sexual assaulters". The so-called "sexual assault" not only includes the behaviors of oral sex, anal sex and sexual intercourse with the juveniles under 12 years old but also includes the behaviors of oral sex, anal sex and sexual intercourse with those above 12 years old. However, the criminal penalty is not applicable for those only committing obscenity and seductive behavior.

In the meantime, some states restrict the age of the executed person. For instance, according to the regulations of criminal law of California, the criminal less than 16 years old cannot be sentenced to the drug treatment unless he is at least three years older than the victim due to the crimes such as sexual assault, rape or incest. In other words, the defendant cannot be judged to the criminal penalty if he is at the similar age of the victim which means their age difference is less than 3 years. Apparently, the young defendants violating the law due to "puppy love" are excluded, which manifests the spirit of persuading and protecting the juvenile criminals.

2) Whether the object is limited to re-offenders

Though chemical castration is proposed to urge the recidivism rate of the sexual crime, it is seldom limited to re-offenders or recidivists according to the legislation of all states in America. Generally, penalty application conditions are different between first offenders and re-offenders. For instance, according to the regulations of criminal codes of California, the court can sentence the drug treatment as the parole condition for the criminals committing sexual crime to the children under 13 years old for the first time. Louisiana regulates based on the nature of the defendant's crime: if the defendant commits sexual crime to the victim under 12 years old, he should accept MPA injection when obtaining parole and suspended sentence even if he committed the crime for the first time; however, the defendant should accept the drug treatment as the condition for obtaining parole and suspended sentence when committing other sexual crimes again.

Some states don't distinguish first offenders and re-offenders, but the judicial organ is authorized to execute discretion. For instance, according to the regulations of the criminal law of Wisconsin, the Department of Corrections can demand the defendant having sexual intercourse with juveniles under 13 years old to accept anti-androgen drug treatment as the condition for obtaining parole. In Montana, the court can sentence the defendant committing the regulated sexual crime and older than the victim by over 3 years old to accept drug treatment. As for the situation of the sentence above, the Department of Corrections or court can execute discretion according to the case.

\subsection{The Position of the Criminal Law of Chemical Castration}

The position of the criminal law of drug treatment indicates the problem that it is the kind of punishment independent of imprisonment or alternation of the imprisonment, latter of which is held in most states. The acceptance of drug treatment is regarded as the condition for obtaining parole and suspended sentence. For instance, in criminal laws of California, the criminal sentenced to the 
drug treatment by the court should accept MPA treatment to obtain parole. Louisiana regulates that the criminals with the qualification for drug treatment cannot obtain parole, suspended sentence or abatement from penalty unless accepting MPA injection. However, there are few states take drug treatment as the accessory penalty. That is, the criminals will be sentenced to the MPA treatment when sentenced to criminal penalties such as punishment against freedom. In this way, drug treatment is not the condition for obtaining parole, suspended sentence or abatement from penalty. Meanwhile, the criminals cannot obtain abatement from penalty or be released in advance. For instance, according to the regulations of the criminal law of Florida, other penalties under the item (the article 794.011) should not be changed or abated if the court sentences the defendants to the drug treatment. Under such legislation, the criminal should serve the sentence in the prison and also should continue accepting anti-androgen treatment after release, the latter of which doesn't offset the condition for the former.

\subsection{Replacement of Penalty Execution}

Whether the criminal has other alternative judicial scheme to choose if not accepting drug treatment? In the state where chemical castration is regarded as the kind of independent penalty, the more severe chemical castration is the only choice. That is, the criminal's testicle is excised through surgical operation to perpetually deprive his reproductive function. For example, Florida regulates that the court can sentence surgical castration as the alternative penalty of drug treatment if the defendant submits written application saying that he knows, understands and is willing to accept surgical castration. On the other hand, the criminals can choose surgical castration or serve the sentence in prison in the state where chemical castration is regarded as the condition for parole, suspended sentence or abatement from penalty.

\subsection{Guarantee of Penalty Execution}

Drug treatment is usually the condition for the sexual offenders to obtain parole. Therefore, how to guarantee the criminals accept the drug treatment consciously after the release? The criminals will suffer from severe punishment if evading treatment after being released. Furthermore, the criminals will be put in prison in the state where drug treatment is regarded as the condition for parole. For instance, Louisiana regulates that the parole, suspended sentence or abatement from penalty will be canceled and "good time" obtained in the prison before will be also canceled if the defendant doesn't accepts drug treatment. Criminals who refused to take the MPA treatment will be punished as a heavily in the states where drug treatment is regarded as the kind of independent penalty. Florida regulates: the defendant will be punished as the level 2 heavy offense and may be sentenced to 15 years' imprisonment and fined 10,000 dollars if refusing cooperation or MPA treatment. Montana legislators take this more serious. The defen- 
dant will be sentenced to the imprisonment of over 10 years and 100 years below without possibility of parole as considered to contempt of court for refusing to accept drug treatment.

\section{Legitimacy Argument on Chemical Castration}

Like other new legal systems, chemical castration also provokes huge controversy in America. The supporters and opponents mainly focus on issues of constitutionality, effectiveness, fairness and economy. In this part, I will first study opinions from the objectors. Then I will refute these arguments and try to demonstrate the justification of chemical castration.

\subsection{Reasons for Opposing the Chemical Castration}

1) Against the principle of prohibiting torture

The opponents think that chemical castration indicates the castration, belonging to the cruel torture prohibited according to the US Constitution. According to the $8^{\text {th }}$ amendment to the US Constitution, "the principle of prohibiting cruel and abnormal penalty" is determined, according to which the US Supreme Court determines three standards for judging cruel and abnormal penalty $\left.{ }^{5}: 1\right)$ whether the penalty is of inner cruelty; 2) whether the penalty is equivalent to the crime; 3 ) whether the penalty is surplus as far as the realty of legal goal is concerned. Some believe that the chemical castration belongs to cruel penalty according to these three standards.

Firstly, anti-androgen drug will deprive the criminal of sexual lust and function and violate his reproductive right and that to enjoy sexual interest. Meanwhile, these drugs also bring about a series of known side effects and long-term unknown ones (Simpson, 2007: p. 1232). It means that the injection could bring forever harm to the criminals. So it is of inner cruelty.

Secondly, the harshness of drug treatment exceeds the penalty in proportion to the sexual crime. According to the legislation of many states, the final time of MPA treatment is not definitely regulated. However, the hormone level will rise again and the criminal will recommit the crime once the MPA treatment is discontinued. It may cause the authority to ask the criminal to accept MPA injection till death to achieve the effect of preventing recommitment thoroughly, which is equivalent to the lifelong penalty, obvious excessively severe (Stadler, 1997: p. 1323).

Thirdly, all sexual offenders cannot be cured through drug treatment. Doctor Simpson from FSU believes: if chemical castration belongs to the surplus penalty for the criminals not due to the sexual lust as the legislation purpose of reducing the recidivism rate of criminals cannot be fulfilled through MPA injection (Simpson, 2007: p. 1323). Some scholars believe that MPA injection doesn't work for every criminal which means they are injected with ineffective drug

${ }^{5}$ In re Kemmler, 136 US 436 (1890); Wilkerson v. Utah, 99 US 130 (1878); Harmelin v. Michigan, 501 US 957 (1991); Furman v. Georgia, 408 US 238, 279 (1972). 
compulsorily, and this is obviously a surplus penalty (Smith, 2013: p. 258).

2) Indulging sexual offenders.

Drug treatment is usually regulated as the condition for parole and suspended sentence, which means that the sexual criminal can be exempt from the punishment against freedom through MPA injection. The opponents think that the criminal will evade the fact that he should be originally put in prison and it is indulgence on the criminals. As for the occurrence of the murder of Jessica Lunsford surprising all American people in 2015, the only 9-year-old girl Jessica was captured by the criminal at home to his apartment for repeated sexual assault and buried alive three days later (Jim, 2006). The case happened in California which was the first to implement chemical castration. Besides, the outrageous defendant Couey in the case had criminal records of sexually molesting children but obtained parole. He was the applicable object of drug treatment. After the occurrence of this case, Georgia abolished chemical castration in 2006 to conform to the discussion of "punishing the sexual offenders severely".

3) Infringing upon the privacy of the criminals

Firstly, MPA injection infringes upon the reproductive right of the criminal. According to the $14^{\text {th }}$ Amendment to US Constitution, the protection of the right to privacy is affirmed. However, according to the legal precedent of the federal court, the reproductive right of the citizen belongs to one rights to priva$c y^{6}$. Some scholar believes that chemical castration violates the criminal's constitutional right namely the reproductive right for MPA injection will reduce the in vivo hormone of the criminal and his sexual lust. However, to have birth, the criminal should have sexual behavior and then should rely on corresponding sex hormone and lust (Vanz, 1996: A1). Doctor Stadler points out that the drug treatment should be implemented continuously until the authority thinks it is not necessary according to the legal regulations, which means that most criminals may suffer from lifelong penalty. In this way, the sexual and reproductive rights of the criminal will be deprived in life time. The chemical castration is equivalent to the surgical castration in terms of effect (Stadler, 1997: p. 1320).

Secondly, MPA injection infringes upon the criminal's right to reject treatment. For instance, Doctor Simpson adds that the criminal should agree to accept treatment to be executed according to legal regulations. However, they actually don't have the right to reject for the rejection of treatment is to reject the condition for parole (or suspended sentence), the criminal should stay in prison or choose surgical castration (Simpson, 2007: p. 1239). Doctor Daley of Indiana University even angrily asks: whether the criminal's agreement upon the chemical castration is the real choice when facing more severe choice?" (Daley, 2008: p. 101).

4) Equal protection violation

Chemical castration indicates inhibiting the criminal's desire to commit crime by reducing his hormone, but it only acts on male criminals other than females.

\footnotetext{
${ }^{6}$ San Antonio School Dist. v. Rodriguez, 411 U.S. 1 (1973); Skinner, 316 U.S. p.541.
} 
The sexual criminal subjects are not limited to men according to the American criminal law. Females also can be the defendants of sexual crimes, which is to manifest the equal protection spirit of the $14^{\text {th }}$ Amendment to US Constitution. In this case, the criminal law is caught in "constitutional paradox" (Harvard Law Review Association, 1997: p. 802). If the females are regarded as the objects of drug treatment and anti-androgen cannot generate effect of anti-crime for females, the criminal law violates the principle of prohibiting cruel torture due to the redundancy of the penalty. If females are excluded out of drug treatment, they will not entitled to enjoy related suspended sentence and parole and the criminal law will violate the principle of equal protection. Some believe that it is a discrimination against male because most sex offenders are male and chemical castration is a penalty directing at male (Oswald, 2013: p. 485).

5) Flaws in effective data

Criminal psychologist Braford supposes that chemical castration cannot fundamentally solve the problem. The recidivism rate of the criminals will rebound drastically once in the case of drug treatment discontinuance (Bradford, 1983: p. 723). On the other hand, scholar Gilchrist of the University of Southern California assumes that the recidivism rate data of chemical castration is misleading for the recidivism rate data is excerpted from the self-reports of the criminals accepting drug treatment in the experiment. Actually, the criminals often hide the situation of recommitment for fear of suffering from penalty due to the self-report (Gilchrist, 1998: p. 189). Doctor Stadler assumes that criminals who are willing to participate in the experiment originally have the wish of self-correction. However, many criminals lack the motivation of self-upgrading in practice. Therefore, the actual effect of drug treatment is not as perfect as the experimental data indicates (Stadler, 1997: p. 1316).

\subsection{Reasons for Supporting Chemical Castration}

However, the above-mentioned objections are invalid. Chemical castration is a humane, efficient, low-cost, and feasible penalty for pedophilia crimes.

1) Consideration is given to the capacity of prison and protecting the society

The most important reason to support chemical castration is that it plays an obvious role in preventing sexual crimes. The recidivism rate of the criminals with conditional release reaches as high as above $50 \%$ in western countries. However, in the group that accept MPA injection, the recidivism rate is averagely lower than $15 \%$ and the lowest is only $2.2 \%$. Another study found that child molesters had a $36.9 \%$ recidivism rate, and rapists had a $46.2 \%$ rate, a much higher rate than other crimes, but chemical castration can cut rates of reoffending from more than $40 \%$ to just 5\% (Cauley, 2014: p. 507). Chemical castration can make sexual offenders gradually relieve the abnormal needs and sexual desires to control their own behavior, and the criminals can return to society better after the treatment (Hou, 2017: p. 88). The opponents believe that the data may be based on the criminals' false "self-report", which inherently cannot be denied. 
However, the figure about recidivism in related research also includes the cases investigated by the police, which is real. The proportion of the recidivism rate of the criminals investigated by the policy after drug injection is far lower than that before application, which simply explains it still plays an obvious role in preventing sexual crime.

Such criminal penalty is denied for the recidivism rate may rise after drug discontinuance. The common flaw for most criminal penalties is that the recidivism rate will rise again after the execution of criminal penalty is suspended. For example, the recidivism rate after the criminal is paroled is absolutely higher than that in prison, but it doesn't mean that the punishment against freedom is ineffective. The research shows that the recidivism rate of the criminal is still lower than that before drug application even if drug injection is discontinued (Gagne, 1981: p. 645). It indicates that anti-androgen still has lasting effect after drug discontinuance.

The supporters believe that such opportunity is for mitigating the pressure of prison and protecting victims from being infringed upon by the criminal again. US scholars believe that prisons in most states of American have been filled with the criminals and the system of taking considerations into the discretionary release including suspended sentence and parole has already been the important measure for each state to mitigate the pressure of prison. Scholar Gimino of Peppenerdine University says that the government is in a dilemma of saturating the capacity of the prison and high recidivism rate for the recidivism rate of the group under conditional parole usually exceeds 50\%. By taking MPA treatment as the condition for suspended sentence or parole, the number of criminal serving the sentence in prison and recidivism rate can be reduced (Gimino III, 1998: p. 101). Overcrowded prisons can easily intensify contradictions within prisons, thereby jeopardizing the safety of inmates and guards. MPA therapy can better protect society, inmates and guards (Cauley, 2014: p. 513).

There is concern for the reliability and effectiveness of this sexual crime precaution because there have been only 8 states that include the drug treatment into the criminal law and 2 states even have cancelled the criminal punishment up to the present. The legislation process is slow. Actually, there are complicated reasons for observation and repetition of legislation in numerous states in America. Firstly, the legislation procedure in states of America is complicated, including procedures such as proposing the bill, investigations held by special committee, and submitting to the one institution for consideration (e.g.: Senate), and then submitting to another institution (e.g.: House of Representatives) for consideration after being passed, negotiation between the two institutions and approval of the bill, etc., in which also involves the conflict between the republic and democratic party. Thus, the drug treatment bill in many states is still in the legislative process. Secondly, some people and senators and representatives still have misunderstanding about drug treatment and take it as physical castration in the same way, so a long process of popularization of science and persuasion is 
needed. Thirdly, American doctors usually reject serving as the state's "executioners" out of occupational culture. AMA strongly opposed against cracking down on criminals by taking medical method as criminal one, thus Oregon abandoned the punishment for not finding out the execution doctors ${ }^{7}$. However, the abovementioned reasons are mainly about legislation and cultural concept of America, which are not relevant to the safety and effectiveness of the drug treatment. On the other hand, we shall see that more and more countries include drug treatment into the criminal code. Many countries including Denmark, Germany, Italy, Sweden, Switzerland, Columbia, Salvador, Argentina, Poland and Korea have already established this penalty. Meanwhile, other countries including Britain, France, New Zealand, India and Indonesia have included it into the process of legislation. It thus can be seen that chemical castration is being vigorously developed as it has already been evolved into the trend of global criminal legislation thanks to its efficiency and safety.

2) Lower cost for penalty execution

The highly-lower cost compared with the imprisonment punishment is also an important reason for people to support chemical castration. The American government spends 25,000 US dollars in detaining every criminal each year. However, the actual expense is a lot higher for this figure doesn't include projects such as building new prisons (Gimino III, 1998: p. 101). Some research points out that the expense for detaining the serious criminals accounts for $0.5 \%$ - 0.7\% of American GNP (Harrison, 2007: p. 19). In the traditional imprisonment punishment, criminals still can be sentenced to involuntarily commitment even after gaining parole from the prison, namely accepting mandatory treatment in hospital, which further increases the fiscals of the government. The expenditure of each state for preventive detainment ranges from 500 thousand US dollars to 450 million US dollars (Wash. St. Inst. for Pub. Pol'y, 2005: p. 2). The expense of chemical castration is only 160 US dollars for each person and less than 2000 US dollars every year. In addition, according to the legislation of Iowa and Louisiana, the criminals accepting MPA injection should undertake the expense independently, thus the cost for execution is lower (Tullio, 2009: p. 208).

MPA used for penalty execution in America is also a cheap contraceptive in China. Its online sales price is $\$ 2.7 / 200 \mathrm{mg}$ (Jiankang Website, 2008). According to the dosage of the Courts of United States namely $500 \mathrm{mg} /$ person every week, the cost of drug for execution is less than 700 Yuan/person every year, which is obviously lower than that for detaining the criminals.

3) Meeting "the principle of prohibiting cruel torture"

As for the accusation that "chemical castration is cruel torture", the supporters defend MPA injection by focusing on the triple standards of the federal court on cruel torture:

Firstly, chemical castration, not indicating "the castration" in real sense, is of no internal cruelty for it will not cause physical disability of the executed person

${ }^{7}$ People v. Gauntlett, 352 N.W.2d 310, 318 (Mich. Ct. App. 1984). 
as a kind of anti-androgen drug muscular injection. Its influence on body is completely reversible. The androgen of the executed person will be instantly recovered to the normal level and his sexual function will not be damaged once in the case of drug discontinuance (Gimino III, 1998: p. 88). Those who mention chemical castration as corporal punishment in the same breath actually have serious misunderstanding about it. Chemical castration, is not the castration in traditional sense, but a reversible drug treatment approach. The drug injection doesn't destroy the completeness of the body. It is a treatment approach inhibiting the excessive hormone of the criminal within certain period by taking chemical drug as a method. More importantly, the effect of the treatment is reversible. That is, the androgen of the criminal can be gradually recovered after drug discontinuance without perpetual harm caused to the criminal. Some believe that drug treatment will infringe upon the criminal's right of self-determination about medical treatment as mandatory treatment. However, chemical castration belongs to the criminal punishment, which is always mandatory. Any treatment is not the punishment if agreed upon by the criminal. According to the regulations of the $18^{\text {th }}$ article of Chinese criminal law, the mental patients can be compulsorily treated by the government if necessary which means that mental patients not constituting the crime can be compulsorily treated. With the concept of listing the light to show the serious, there is no doubt that compulsory treatment is applicable for sexual offenders.

Secondly, chemical castration meets the equivalence between crime and punishment. On one hand, drug injection will not cause excessive pain and discomfort. Contrarily, the sexual lust of the criminal can be reduced through treatment, and the criminal is get rid of abnormal and painful sexual fantasy (Gimino III, 1998: p. 89). According to the research of Denmark scholars, 90\% of criminals accepting castration say that they are satisfied with the execution effect (Winslade, 1998: p. 375). On the other hand, sexual crime will not only infringe upon other's freedom but also cause lifetime physical and mental trauma especially for child victims. They will form "psychological timing bomb" hereupon and have disorder in personality in the future (Fitzgerald, 1990: p. 38). Compared to the perniciousness of the sexual crime, the drug treatment is a mild treatment.

Thirdly, chemical castration is necessary to realize legislation purpose. The purpose of sexual crime law is to prevent sexual crime. Anti-androgen injection is to realize the purpose. Besides, its harm is even less than that caused by imprisonment or surgical castration and there is no such problem as excessive criminal punishment. To be frank, such treatment is not effective to all criminals especially the female criminals. However, its application can be controlled by setting identification procedure. It is just a problem about improvement of procedure and cannot become the reason for denying chemical castration (Flack, 2005: p. 184).

4) Rational intervention in the right to privacy 
The supporters believe that chemical castration, a reversible medical treatment approach, rationally intervenes in the criminal's right to privacy. Firstly, it doesn't completely deprive the criminal of the reproductive right. Doctor Gimino points out that the drug will reduce the criminal's lust but not thoroughly deprive his sexual function. Medical research shows that the patient can still have sexual life under the assistance of the mate or researcher. Therefore, it's believed that it is a misunderstanding that chemical castration will deprive the criminal's reproductive right just like surgical castration (Gimino III, 1998: p. 93). Tullio believes that chemical castration is legitimate even if it weakens the criminal's reproductive right for there is weigh and balance on interests. That is it exempts the children from harm. Additionally, the children's personal safety is more important than the sexual offender's reproductive right (Tullio, 2009: p. 217).

Secondly, it just restricts the criminal's right to choose treatment rationally. The supporters further point out that the drug treatment doesn't infringe upon the right to choose the drug treatment that the constitution endows with the citizens. On one hand, in informed consent procedure, the criminal can make choice between surgical castration and drug injection. In the state where drug treatment is considered to be the condition for parole or suspended sentence, the criminal can choose to serve the sentence in prison (Fitzgerald, 1990: p. 43). In other words, the criminal is entitled to reject drug treatment. On the other hand, as pointed out by Doctor Peters, the drug treatment doesn't infringe upon criminals' constitutional right even if their right of choice is limited, the reason for which the citizens' right of choice can be restricted by law according to the legal precedent of the federal court if related national benefits are more important. These national benefits include: protection of life, prevention of suicide, protection of innocent the third person, and protection of professional medical fields. The compulsory treatment of anti-androgen protects potential victims of sexual offences, which is accordance with "the protection of innocent third people" (Peters, 1992-1993: p. 323). Some also adopt the concept of "listing the light to show the serious": the federal court says that milder anti-androgen treatment also should meet constitution as the mandatory reproduction of the mental patients and antipsychotic drug of the criminal doesn't violate the constitution (Gimino III, 1998: p. 94).

5) Accord with the modern criminal penalty concept

A criminal penalty cannot become legitimate if it cannot be accepted by the society. However, Doctor Peters points out that the name of chemical castration is terrifying but it is just a reversible drug treatment essentially. The public can accept it just like the traditional punishment. Firstly, the intervention degree of anti-androgen treatment is just about the same as traditional drug treatment (e.g. anti-depression, mental disease and tranquilizer) for the criminals. Secondly, if people can accept the court sentencing the criminals to life imprisonment without parole, they can also accept the lifelong anti-androgen treatment. 
Thirdly, if the society admits the country is entitled to sentence the criminals to death, the sexual lust control treatment which is milder than the death penalty could also be accepted by the society (Gimino III, 1998: p. 90).

6) Chemical castration is not sexist.

Drug treatment will not deprive the criminals' reproductive right or female criminals' right of equality. On one hand, the criminals still can have sex under the assistance of their mates, so their reproductive right will not be infringed. Besides, without drug treatment, the criminals will lose the opportunity for parole and still have to serve the sentence in prison due to the high possibility of recommitment. In this way, they certainly cannot execute the reproductive right. On the other hand, although anti-androgen injection is not applicable for female criminals, it doesn't constitute discrimination. The principle that men are all equal in front of criminal law doesn't prohibit all kinds of legal differences but unreasonable ones. The restraining nature of criminal law demands that ineffective penalties cannot be applied. The reason for the inapplicability of the drug injection therapy for female criminals is its lack of effectiveness in crime prevention and this is not an unreasonable difference. It's the result of the objective functions of the penalty itself. For example, the court will not sentence confiscation of property to the homeless. Obviously, it is not an unreasonable difference.

7) Drug treatment is the manifestation of criminal penalty mitigating.

The accepting of anti-androgen treatment is usually the condition for parole and abatement from penalty in countries where chemical castration is implemented. It means that there are more opportunities for parole in advance for criminals who should serve the sentence in prison if they accept chemical castration. In the premise of ensuring the criminals won't endanger the society any more, unnecessary imprisonment is avoided through drug treatment. Thus, the inhibition of criminal penalty is manifested.

8) Practical feasibility

It is practically feasible to let the criminals accept drug treatment. Some may worry that the main objects of drug treatment are the released criminals. This system of chemical castration is not feasible if the offender cannot voluntarily receive medical treatment after his release from prison. It should be admitted that not all criminals will be willing to accept drug treatment. However, related research shows that there indeed are a lot of criminals willing to cooperate with treatment, which is related to the criminology of sexual criminals. According to Hottle's classification of sex crimes mentioned above, the fourth type of criminals are those committed crimes out of abnormal sexual preferences such as pedophilia. The chemical castration is most suitable for this type of criminals for they usually commit crime because they can't control their lust. However, they can also realize that their behavior is not tolerable. They usually regret and have strong desire for treatment and wish to get rid of lust and wrong behaviors through treatment after committing the crime. Therefore, they will actively accept drug injection and obtain "positive effect" (Hottle, 1992-1993: p. 307). In fact, the majority of criminals can cooperate with drug therapy on time in pe- 
nalty execution practices of western countries. There is still few escaping from the therapy, but it's just a small number for they will face serious punishment measures including being put in prison instantly once in case of violating the regulations of drug treatment. Therefore, the feasibility of the penalty execution can be enhanced by designing specific criminal penalty system. Firstly, identification procedure can be set to choose criminals who have consciousness of repentance and desire for seeking medical treatment and for whom the drug treatment is applicable. Secondly, drug treatment shall be combined with mandatory punishment. The criminal should be severely punished if not accepting injection as scheduled (e.g.: parole is canceled).

\section{Local Construction of Chemical Castration}

\subsection{Range of Applicable Accusation}

The author thinks that the applicable accusation of chemical castration shall be limited to the criminals sexually molesting children. Though the criminal's sexual lust can be reduced through drug treatment and it plays an obvious role in urging all sexual criminals, general sexual criminals are not the applicable criminal type of drug treatment. The main objects of drug treatment are paroled criminals because it is highly impossible for the detaining the criminals to recommit sexual crimes which means that it is unnecessary to apply the drug therapy on them. In this way, it is necessary for the criminals to accept injection actively in the designated medical institution. However, according to the study on the types of sexual criminals implemented by Hottle, general sexual criminals (the former three types) don't have desire for seeking medical treatment and may not cooperate with the drug treatment actively after paroled. Only the fourth type of criminals namely those committing crime out of abnormal sexual preferences and psychological disorder is willing to cooperate with the drug therapy who usually show a strong repentance and a desire for seeking medical treatment after committing the crime. However, only pedophilia behavior of the abovementioned morbid behaviors constitutes crimes in Chinese criminal law. The criminal research shows that the characteristics of pedophilia is that the criminal is highly sexually excited after contacting a child, and it is hard for him to inhibit the criminal activity even if facing the extreme penalty (Flack, 2005: p. 173). The pedophilia criminal's desire to commit crime can be inhibited by controlling his hormone with drug so that the crime could be prevented. Therefore, the applicable accusation of chemical castration in Chinese criminal law shall be limited to the accusation of sexually molesting child: rape crime (carnal abuse), child molestation, crime of prostituting little girls, and the crime of abducting and trafficking children (in the case of legal circumstance that the little abducted girls are raped).

\subsection{Applicable Objects}

First, the application of chemical castration is limited to male criminals above 18

(Han \& Zhang, 2016: p. 43). Estrogen does harm to the growth of juveniles. In 
order to avoid permanent damage to the criminals, chemical castration cannot be applied to juvenile criminals. Besides, it cannot be applied to female criminals due to its ineffectiveness.

Second, whether chemical castration is only limited to the sexual criminals recommitting the crime? The answer is no. The purpose of drug treatment is to control the recidivism rate of the sexual criminal and its applicable objects shall be the ones with higher possibility of recommitment. And whether the criminal is a first offender or a recidivism is only of reference value rather than the decisive factor. Therefore, it is necessary to imitate the legislation of Montana. That is, there will not be a stiff regulation on whether the chemical castration is applicable for the criminal but a discretion for the judge who will decide based on the behavior of the criminal and the expert's report on the criminal's personality and mental condition. However, the juvenile criminals shall be excluded out of the applicable objects of drug treatment for they are at growth and development stage. Their development may be influenced and lifelong harm may be caused if their androgen is inhibited compulsorily.

\subsection{Position in the Criminal Law}

Apparently, drug treatment can't be considered to be the principal penalty for there is only one principal penalty of crime. Medical method cannot replace punishment against freedom or the criminal penalty will be too mild. Similarly, it shall not be regarded as the condition for suspended sentence for the sexual crime in Chinese criminal law is grave crime. The criminal can be sentenced to the suspended sentence if accepting treatment which is obviously an indulgence. It shall not be regarded as the accessory penalty for the main objects of chemical castration are paroled criminals. Thus, it is necessary to ensure that the criminal accepts injection regularly through severe punishment measures. However, there is a lack of such punishment measures for accessory penalty in China. Therefore, drug treatment shall be regarded as the condition for parole. That is, the criminal should accept an-androgen injection after paroled during the execution. If the criminal fails to accept drug injection in the designated medical institution regularly according to the regulations, the judicial organ can cancel parole and put him in prison to guarantee him accepting drug treatment. However, before execution, the criminal's right of informed consent should be guaranteed so that the criminal can decide whether to accept the drug treatment or not under the condition of knowing about the risks in anti-androgen, expected result and possible alternative solutions. Of course, the criminal will not be paroled if refusing to accept drug injection.

\subsection{Identification Procedure for Penalty Execution}

Not all sexual criminals whose victims are children shall accept drug treatment. If the criminal has sexual intercourse with the little girl out for love, there is no high possibility for recommitment and the drug treatment is not necessary. Anti-androgen may not be effective to all sexual criminals, like female ones. In the 
meantime, drug may have strong side effects on criminals with physical abnormality and in this case, the penalty is not applicable, either. Besides, if the criminal doesn't commits the crime due to morbid lust or lacks of repentance or desire for seeking medical treatment, the purpose of crime prevention may not be fulfilled through drug treatment. Therefore, before the execution, the court shall identify the situation and judge whether chemical castration is applicable for the criminal. Identification procedure shall include two stages: firstly, medical and psychological experts should evaluate physiological, mental and personality condition of the criminal to identify whether the treatment is suitable for the criminal. Secondly, the court should decide whether the criminal should accept drug treatment according to the experts' opinions and the performance of the defendant during litigation.

\subsection{The Term of Penalty Execution}

There is timeliness in curative effect of drug injection, so the criminal should accept injection one week before paroled and also shall continue accepting muscular injection within a period of time after paroled. Speaking of the terminal time of penalty execution, the penalty execution organ should not be given the absolute power to decide as it is in the criminal law of California for it is equivalent to an indeterminate sentence. However, if the law gives the court the power to decide the term of penalty at the very beginning just like Florida, there will be a problem of ignoring the criminal's correction. The proper practice is that the court shall determine the longest term of penalty for the criminal to accept injection when making judgment, and shall also pay close attention to the criminal during the penalty execution regularly. If it is no longer necessary to implement drug treatment according to the mental and personality evaluation of the criminal, the court can decide to terminate the drug injection in advance.

\section{Conflicts of Interest}

The authors declare no conflicts of interest regarding the publication of this paper.

\section{References}

Blume, S. (1990). Secret Survivors: Uncovering Incest and Its Aftereffects in Women. New York, NY: Ballantine Books.

Bradford, J. (1983). Research on Sex Offenders: Recent Trends. Psychiatric Clinics of North America, 6, 715-731.

Brody \& Green (1994). Washington State's Unscientific Approach to the Problem of Repeat Sexual Offenders. The Bulletin of the American Academy of Psychiatry and the Law, 22.

Cauley, R. (2014). Is Chemical Castration a Progressive or Primitive Punishment? Balls Are in Your Court, Iowa Legislature. The Journal of Gender, Race and Justice, 17, 493.

Chinese Children's Culture and Art Foundation (2016). Education Investigation Report on Child Sexual Assault Prevention. 
http://gongyi.ifeng.com/a/20170303/44550261_0.shtml

Daley, M. V. (2008). A Flawed Solution to the Sex Offender Situation in the United States: The Legality of Chemical Castration for Sex Offenders. Indiana Health Law Review, 5, 88-121.

Fitzgerald, E. A. (1990). Chemical Castration: MPA Treatment of the Sexual Offender. The American Journal of Criminal Law, 18, 1-57.

Flack, C. (2005). Chemical Castration: An Effective Treatment for the Sexually Motivated Pedophile or an Impotent Alternative to Traditional Incarceration? Journal of Law in Society.

Gagne, P. (1981). Treatment of Sex Offenders with Medroxyprogesterone Acetate. American Journal of Psychiatry, 138, 644-646.

Gang, T. (2017). Prevention Mechanism of Sex Offenders Re-Offending. Political and Legal Forum, 3, 57-68.

Gilchrist, C. (1998). Examination of the Effectiveness of California's Chemical Castration Bill in Preventing Sex Offenders from Reoffending. Southern California Interdisciplinary Law Journal, 7, 181-203.

Gimino III, P. J. (1998). Mandatory Chemical Castration for Perpetrators of Sex Offenses against Children: Following California's Lead. Pepperdine Law Review, 25, 67-105.

Guangdong Provincial Procuratorate \& Guangdong Women's Federation (2012). Report on Sexual Assault of Girls. http://www.doc88.com/p-7377012322276.html

Han, W., \& Zhang, J. (2016). Analysis on the Feasibility of Establishing Chemical Castration System in China. Journal of Changchun University of Science and Technology (Social Sciences Edition), 1, 40-56.

Harrison, K. (2007). The High-Risk Sex Offender Strategy in England and Wales: Is Chemical Castration an Option? The Howard Journal of Criminal Justice, 46, 16-31. https://doi.org/10.1111/j.1468-2311.2007.00451.x

Harvard Law Review Association (1997). California Becomes the First State to Require Chemical Castration of Certain Sex Offenders. Harvard Law Review, 110, 799-804.

Hottle, D. M. (1992-1993). Chemical Castration: An Alternative to Incarceration. Duquesne Law Review, 31, 307-328.

Hou, W. F. (2017). Feasibility Study on Applying Chemical Castration System in China. Criminal Research, 5, 83-89.

Hunter, M. (1990). Abused Boys: The Neglected Victims of Sexual Abuse. Lanham: Lexington Books.

Jiang, M. (2008). Etiology, Evaluation and Treatment of Pedophilia. China Journal of Health Psychology, 5, 568-571.

Jiankang Website (2018). http://www.jianke.com/product/03189.html

Jim, R. (2006). Judge: Couey Confession Out. St. Petersburg Times.

Kravitz, H. M. et al. (1995). Medroxyprogesterone Treatment for Paraphiliacs. The Bulletin of the American Academy of Psychiatry and the Law, 23, 19-33.

Liu, J. (2017). On Child Molestation and Its Prevention Strategy. Crime Research, 3, 78-84.

Liu, L. (2001). On the Means of Labor Correction in China's Prison System. Jiangsu Social Sciences, 1, 149-152.

Max \& Engels (1972). The Complete Works of Marx and Engels (Vol. 31). Peking: People's Publishing House.

Max \& Engels (1979). The Complete Works of Marx and Engels (Vol. 42). Peking: 
People's Publishing House.

Office of Governor Pete Wilson (1996). Chemical Castration Fact Sheet.

Oswald, Z. E. (2013). "Off with His _": Analyzing the Sex Disparity in Chemical Castration Sentences. Michigan Journal of Gender and Law, 19, 471.

Peters, K. A. (1993). Chemical Castration: An Alternative to Incarceration. Duquesne Law Review, 31, 307.

Rundle, R. L. (1996). Will “Chemical Castration” Really Work?

Simpson, T. (2007). Florida's Chemical Castration Statute Misses the Mark. Florida State University Law Review, 34, 1221-1246.

Smith, H. A. (2013). Common Enemy and Political Opportunity Leave Archaically Modern Sentencing Unchecked: The Unconstitutionality of Louisiana's Chemical Castration Statute. Loyola Law Review.

St. Louis Post-Dispatch (1996). Chemical Castration Seems to Be Working in Denmark.

Stadler, A. (1997). California Injects New Life Into an Old Idea: Taking a Shot at Recidivism, Chemical Castration, and the Constitution. Emory Law Journal, 46.

Taylor, R., \& Kirk, D. (1987). Representing Sex Offenders and the Chemical Castration Defense, 34 American Jurisprudence Trials. New York, NY: Lawyers Cooperative Publishing.

Tullio, E. M. (2009). Chemical Castration for Child Predators: Practical, Effective, and Constitutional. Chapman Law Review, 13, 191-220.

Vanzi, M. (1996). Assembly OKs Castration Drug for Molesters. L.A. Times.

Wang, L. (2010). Research on Criminal Labor Reform in the Background of Prison System Reform. China Judicature, 7, 43-47.

Wash. St. Inst. for Pub. Pol'y. (2005). Involuntary Commitment of Sexually Violent Predators. Comparing State Laws, Doc. No. 05-03-1101.

Winslade, W. (1998). Castrating Pedophiles Convicted of Sex Offenses against Children: New Treatment or Old Punishment? SMU Law Review, 51, 349-412.

Wu, X. (1995). The Relationship between Sex Hormones and Male Sexual Crimes. Chinese Journal of Endocrinology and Metabolism, 1, 25-27. 